\title{
UJIAN OSCE REGULER BERORIENTASI ERGONOMI MENINGKATKAN KINERJA PENGUJI DI FAKULTAS KEDOKTERAN UNIVERSITAS ISLAM AL-AZHAR MATARAM
}

\author{
Iing; I Dewa Putu Sutjana; Ida Bagus Alit Swamardika \\ Program Studi Magister Ergonomi-Fisiologi Kerja, Program Pascasarjana \\ Universitas Udayana
}

\begin{abstract}
ABSTRAK
Objective Structured Clinical Examination (OSCE) reguler merupakan ujian ketrampilan klinis di Fakultas Kedokteran Universitas Islam Al-Azhar Mataram. Penguji OSCE merupakan dokter yang juga dosen terlatih dalam menilai ketrampilan klinik mahasiswa. Penelitian ini dilakukan untuk mengkaji secara terukur apakah Ujian OSCE reguler berorientasi ergonomi yaitu dengan peregangan otot dan pemberian teh manis dapat meningkatkan kinerja penguji di Fakultas Kedokteran Universitas Islam Al-Azhar Mataram. Peningkatan kinerja dinilai dari indikator menurunnya keluhan berupa kebosanan, kelelahan dan keluhan muskuloskeletal.
\end{abstract}

Metode yang digunakan dalam penelitian ini adalah metode penelitian eksperimental menggunakan rancangan sama subjek atau treatment by subject design. Sampel yang digunakan sebanyak 18 orang dan memperoleh dua perlakuan yaitu Periode Pertama, subjek tanpa intervensi ergonomi yaitu menguji tanpa peregangan otot dan tanpa pemberian teh manis dan Periode Kedua subjek dengan intervensi ergonomi yaitu menguji dengan peregangan otot dan pemberian teh manis. Kebosanan diukur dengan kuesioner kebosanan. Kelelahan secara umum diperoleh melalui pengisian kuesioner 30 items kelelahan dari IFRC (Industrial Fatigue Research Committee) Jepang. Keluhan otot skeletal diprediksi dengan kuesioner Nordic Body Map. Data dianalisis dengan menggunakan uji normalitas dan uji t-berpasangan pada taraf kemaknaan 5\%.

Hasil analisis menunjukkan bahwa terjadi perbedaan yang signifikan (p $<0,05)$ pada rerata skor kebosanan, kelelahan dan keluhan muskuloskeletal. Rerata skor kebosanan Periode Pertama yaitu 39,724 dan Periode Kedua yaitu 26,415. Terjadi penurunan rerata kebosanan sebesar 33,5\%. Rerata skor kelelahan Periode Pertama yaitu 44,050 dan Periode Kedua yaitu 23,525. Terjadi penurunan kelelahan pada Periode Kedua sebesar 46,59\%. Rerata skor keluhan muskuloskeletal Periode Pertama yaitu 39,25 dan Periode Kedua yaitu 14,02. Terjadi penurunan rerata keluhan muskuloskeletal sebesar $64,28 \%$.

Disimpulkan bahwa intervensi ergonomi berupa peregangan otot dan minum teh manis di sela proses menguji dapat menurunkan kebosanan, kelelahan dan keluhan muskuloskeletal secara bermakna sehingga terjadi peningkatan 
kinerja pada penguji OSCE reguler di Fakultas Kedokteran Universitas Islam AlAzhar Mataram.

Kata kunci: OSCE, Orientasi Ergonomi, Kinerja.

\title{
ERGONOMIC-ORIENTED REGULAR OBJECTIVE STRUCTURED CLINICAL EXAMINATION IMPROVE THE EXAMINERS PERFORMANCE IN THE FACULTY OF MEDICINE AL-AZHAR ISLAMIC UNIVERSITY MATARAM
}

Iing; I Dewa Putu Sutjana; IdaBagus Alit Swamardika

Magister Program in Ergonomic-Work Physiology, Postgraduate Program, Udayana University

\begin{abstract}
Regular Objective Structured Clinical Examination (OSCE) was a clinical skill test in the Faculty of Medicine Islamic University Al-Azhar Mataram. Examiner of OSCE in this study was a doctor who was also a lecturer trained in judging student's clinical skills. The study aimed to know whether ergonomic-oriented regular OSCE by muscle stretching and drinking sweetened tea can improve the performance of examiners in the Faculty of Medicine Islamic University Al-Azhar Mataram. Performance improvement indicators used were decreased complaints of boredom, fatigue and musculoskeletal.

Methods used in this study was experimental study with "treatment by subject design". The study used as many as 18 sample given two treatment which was the first period without the ergonomic intervention involving stretching of the muscle and drinking sweetened tea and the second period was a group with ergonomic intervention. Boredom was measured by a boredom questionnaire. Fatigue, was measured from 30 items of fatigue questionnaire from Japan IFRC (Industrial Fatigue Research Committee). Skeletal muscle complaints was predicted from Nordic Body Map questionnaire. Data were analyzed by normality test and t-paired test with significancy level of 5\%.

The results of this study showed that there was a significant difference $(p<0,05)$ in average score boredom, fatigue and musculoskeletal complaints. The mean boredom score in the first period was 39,724 and in the second period was 26,415 with reduction in average boredom score was $33.5 \%$. Fatigue mean score in the first period was 44,050 and the second period was 23,525 with reduction of fatigue score was 46,59\%. Mean musculoskeletal complaints score in the first period was 39,25 and the second period was 14,02 with reduction in mean musculoskeletal complaints score was $64,28 \%$.
\end{abstract}


It can be concluded from this study that ergonomic intervention by muscle stretching and drinking sweetened tea in the interrupted time of examination process improved the performance of OSCE examiner in terms of boredom, fatigue and musculosceletal complaints in the Faculty of Medicine of Islamic University Al-Azhar Mataram.

Keywords: OSCE, Ergonomic Orientation, Performance

\section{I.PENDAHULUAN}

Saat ini uji kompetensi untuk mendapatkan surat ijin praktik dokter dilakukan dengan menitikberatkan pada uji pengetahuan dalam bentuk ujian pilihan ganda. Metode ini kurang menggambarkan kompetensi lulusan karena aspek keterampilan klinik dan perilaku kurang teruji. Hal ini semakin mendorong diterapkannya metode uji keterampilan klinik, salah satunya adalah Objective Structured Clinical Examination (OSCE) (Dikti, 2006)

OSCE adalah suatu metode untuk menguji kompetensi keterampilan klinik secara objektif dan terstruktur. Subjektivitas dapat dihindari dengan menggunakan metode ini, karena penguji menilai berdasarkan apa yang dilakukan peserta kemudian mencocokkannya dengan kriteria penilaian yang ada, bukan berdasarkan pengetahuan penguji.

Fakultas Kedokteran Universitas Islam Al-Azhar (FK UNIZAR) Mataram menerapkan tiga jenis OSCE. Pertama, OSCE Reguler dilakukan setiap akhir modul. Kedua, OSCE Komprehensif merupakan OSCE yang dilakukan setelah mahasiswa menyelesaikan program pendidikan sarjana kedokteran. Ketiga, OSCE Nasional diselenggarakan mengikuti kalender Uji Kompetensi Dokter yang telah ditetapkan Panitia Uji Kompetensi, yaitu empat kali dalam satu tahun.

OSCE reguler di FK UNIZAR terdiri dari enam stasiun dengan alokasi waktu mengerjakan soal bagi peserta ujian adalah 10 menit setiap stasiun, jadi total satu putaran OSCE adalah 60 menit. Jumlah peserta ujian adalah 60 orang. Sehingga total ada 10 kali putaran ujian OSCE. Jika masing-masing putaran 60 menit, maka total ujian adalah 600 menit atau 10 jam. Penguji bekerja monoton selama kurang lebih 10 jam, karena harus menguji hal yang sama berulang-ulang. Penguji OSCE mutlak harus mengikuti pelatihan cara menjadi penguji yang baik dan bagaimana cara menilai yang benar.

Pada proses kerja yang melibatkan aktivitas fisik dan mental dapat menimbulkan kelelahan umum dan keluhan otot. Hal ini dapat disebabkan oleh waktu yang digunakan melebihi jadwal yang telah ditetapkan, metode yang bersifat monoton, sarana dan prasarana yang tidak sesuai dengan antropometri dan tidak adanya istirahat berupa istirahat aktif yang dilakukan. Dampak yang ditimbulkan dapat mempengaruhi ketelitian, kecepatan, dan konstansi kerja yang pada akhirnya kinerja bisa terganggu (Sutajaya, 2006). 
Kinerja seseorang sangat dipengaruhi oleh beberapa faktor diantaranya kebosanan akibat beban kerja, keluhan muskuloskeletal, dan kelelahan (Mangkuprawira, 2003). Sehingga peningkatan kinerja secara ergonomis dapat diukur berdasarkan beberapa indikator penurunan kebosanan akibat beban kerja, keluhan muskuloskeletal dan kelelahan (Arimbawa, 2010).

Beberapa upaya yang dapat dilakukan untuk mengurangi kebosanan, kelelahan, dan keluhan muskeloskeletal adalah dengan melakukan peregangan, dan pemberian teh manis selama kegiatan menguji. Jika dilakukan dengan perlahan dan fokus, peregangan dapat menjadi alat penghilang stres (Alter, 2003). Teh mengandung kafein, theanine, katekin, dan flavonoid. Menurut Walton (2002; dalam Sofwan, 2013), kafein meningkatkan ketahanan fisik dan menunda terjadinya kelelahan dengan cara meningkatkan kadar serotonin yang ada di otak. Selain itu, kafein dalam teh juga dapat meningkatkan konsentrasi sewaktu bekerja dan dapat memperbaiki mood saat bekerja sehingga membuat suasana kerja menjadi kondusif dan menyenangkan (Sofwan, 2013).

Oleh karena itu perlu dilakukan penelitian tentang ujian OSCE reguler berorientasi ergonomi yaitu dengan melakukan peregangan di sela-sela menguji dan pemberian teh manis dapat menurunkan kebosanan, kelelahan dan keluhan muskuloskeletal sehingga meningkatkan kinerja penguji OSCE di Fakultas Kedokteran Universitas Islam Al-Azhar Mataram.

Dari uraian di atas dapat dirumuskan masalah penelitian yaitu apakah ujian OSCE reguler berorientasi ergonomi yaitu istirahat aktif dengan peregangan dan minum teh manis dapat meningkatkan kinerja penguji berdasarkan indikator kinerja sebagai berikut:

1. Apakah ujian OSCE reguler berorientasi ergonomi dapat menurunkan kebosanan pada penguji OSCE di Fakultas Kedokteran Universitas Islam Al-Azhar Mataram?

2. Apakah ujian OSCE reguler berorientasi ergonomi dapat menurunkan kelelahan pada penguji OSCE di Fakultas Kedokteran Universitas Islam Al-Azhar Mataram?

3. Apakah ujian OSCE reguler berorientasi ergonomi dapat menurunkan keluhan muskuloskeletal pada penguji OSCE di Fakultas Kedokteran Universitas Islam Al-Azhar Mataram?

\section{BAHAN DAN METODE}

Penelitian ini adalah penelitian eksperimental dengan menggunakan rancangan sama subjek atau treatment by subject design. Rancangan sama subjek adalah rancangan serial, karena semua sampel ditetapkan sebagai subjek kontrol dan juga subjek perlakuan, pada periode waktu yang berbeda (Bakta, 2000). Berdasarkan 
rancangan tersebut pengukuran dilakukan dua kali yaitu sebelum perlakuan dan sesudah dilakukan perlakuan berorientasi ergonomi.

Penelitian ini dilaksanakan di Laboratorium Keterampilan Klinis (Skills Lab) Fakultas Kedokteran Universitas Islam Al-Azhar Mataram. Pengambilan data dilaksanakan pada bulan Oktober November 2014. Total sampel yang digunakan adalah 18 orang sampel.

Digunakan kuesioner kebosanan untuk menilai kebosanan dengan lima skala Likert, kuesioner Nordic body map untuk menilai keluhan muskuloskeletal dan kuesioner 30 item kelelahan dengan empat skala Likert untuk menilai kelelahan subjek penelitian.

Hasil penelitian seluruh data variabel yang diteliti berdistribusi normal, maka digunakan analisis statistik parametrik $t$-paired.

\section{HASIL DAN PEMBAHASAN}

Diperoleh bahwa rerata umur penguji OSCE reguler adalah 29,3 \pm 2,3 tahun dengan rentangan $27-32$ tahun. Rerata berat badan penguji OSCE reguler adalah $62,3 \pm 15,7 \mathrm{~kg}$ dengan rentangan $55-78 \mathrm{~kg}$. Rerata tinggi badan penguji OSCE reguler adalah $165,3 \pm 4,7 \mathrm{~cm}$. Dilihat rerata berat badan dan tinggi badan penguji OSCE reguler termasuk dalam rentangan ideal.

Data pada Tabel 1 menunjukkan bahwa kondisi lingkungan dilihat dari suhu, intensitas penerangan, intensitas kebisingan di ruang skills lab pada Periode I (tanpa intervensi ergonomi) dan Periode II (dengan intervensi ergonomi) adalah tidak berbeda bermakna $(p>0,05)$. Ini berarti data kondisi lingkungan pada kedua periode adalah sama.

Tabel 1. Data Kondisi Lingkungan Ruang Skills Lab

\begin{tabular}{llllllll}
\hline No & Variabel & \multicolumn{2}{l}{ Periode I } & \multicolumn{2}{l}{ Periode II } & \multirow{2}{*}{$\mathrm{p}$} \\
\cline { 3 - 5 } & & Rerata & SB & Rerata & SB & & \\
\hline 1 & Suhu ruang $\left({ }^{0} \mathrm{C}\right)$ & 24,4 & 0,38 & 25,1 & 0,29 & $-2,400$ & 0,174 \\
2 & $\begin{array}{l}\text { Intensitas } \\
\text { Penerangan (Lux) }\end{array}$ & 507,6 & 10,17 & 509,2 & 2,54 & $-0,444$ & 0,699 \\
& $\begin{array}{l}\text { Intensitas } \\
\text { Kebisingan (dB) }\end{array}$ & 69,8 & 0,57 & 70,1 & 0,68 & $-1,581$ & 0,169 \\
\hline
\end{tabular}

Hasil uji paired-sample $t$ test terhadap kebosanan sebelum menguji tidak berbeda bermakna ( $p>0,05)$, ini berarti kebosanan sebelum menguji untuk masing-masing periode adalah sama. Sedangkan kebosanan sesudah 
menguji berbeda bermakna $(\mathrm{p}<0,05)$, ini berarti skor kebosanan sesudah menguji untuk kedua periode adalah

Tabel 2 Nilai Rerata Kebosanan antar Perlakuan

\begin{tabular}{|c|c|c|c|c|c|c|}
\hline & \multicolumn{2}{|c|}{ Periode I } & \multicolumn{2}{|c|}{ Periode II } & \multirow[t]{2}{*}{ Nilai t } & \multirow[t]{2}{*}{ Nilai $p$} \\
\hline & Rerata & SB & Rerata & SB & & \\
\hline Sebelum & 37,866 & 6,189 & 38,135 & 6,108 & 2,014 & 0,056 \\
\hline Menguji & & & & & & \\
\hline Sesudah & 77,590 & 10,127 & 64,550 & 8,739 & 3,160 & 0,003 \\
\hline Menguji & & & & & & \\
\hline Beda & 39,724 & 12,172 & 26,415 & 10,233 & 3,231 & 0,003 \\
\hline & & & & $\begin{array}{l}\text { cara } \\
\text { serta }\end{array}$ & kel & $\begin{array}{c}, 05) \\
X\end{array}$ \\
\hline
\end{tabular}

kebosanan pada Periode I (tanpa intervensi ergonomi) yaitu 39,724 dan pada Periode II (dengan intervensi ergonomi) yaitu 26,415. Hasil analisis ini membuktikan bahwa menguji dengan menyisipkan peregangan dan pemberian teh manis mengurangi rerata kebosanan sebesar $33,5 \%$ secara signifikan $(\mathrm{p}<0,05)$ seperti terlihat pada Tabel 2. Hasil ini juga didukung oleh Irwanti (2011) bahwa pembelajaran dengan menyisipkan peregangan mengurangi rerata kebosanan sebesar $18,54 \%$ berbeda. Hal tersebut seperti terlihat dalam Tabel 2.
Hasil uji t-paired skor kelelahan sebelum perlakuan tidak berbeda bermakna $(p>0,05)$, ini berarti skor kelelahan sebelum perlakuan untuk kedua periode adalah sama. Sedangkan skor kelelahan sesudah perlakuan berbeda bermakna $(p<0,05)$, ini berarti skor kelelahan sesudah menguji pada Periode I (tanpa intervensi ergonomi) dengan Periode II (dengan intervensi ergonomi) adalah berbeda. Hal tersebut seperti terlihat dalam Tabel 3.

Tabel 3 Nilai Rerata Kelelahan antar Periode

\begin{tabular}{ccccccc}
\hline & \multicolumn{2}{c}{ Tahap 1 } & \multicolumn{2}{c}{ Tahap 2 } & Nilai t & Nilai p \\
\cline { 2 - 5 } & Rerata & SB & Rerata & SB & & \\
\hline $\begin{array}{c}\text { Sebelum } \\
\text { Menguji }\end{array}$ & 32,225 & 1,819 & 32,225 & 1,847 & 0,001 & 1,000 \\
$\begin{array}{c}\text { Sesudah } \\
\text { Menguji }\end{array}$ & 76,275 & 3,823 & 55,750 & 4,292 & 28,665 & 0,001 \\
Beda & 44,050 & 3,843 & 23,525 & 4,635 & 28,696 & 0,001 \\
\hline
\end{tabular}

Perbedaan rerata skor kelelahan pada Periode I (tanpa intervensi ergonomi) yaitu 44,050 dan pada Periode II (dengan intervensi ergonomi) yaitu
23,525. Terjadi penurunan kelelahan pada perlakuan 2 sebesar $46,59 \%$ secara signifikan $(p<0,05)$ seperti terlihat pada Tabel 3. Temuan ini 
juga didukung oleh Sutajaya (2006) yang menyatakan bahwa pembelajaran sistemik, holistik, interdisipliner, dan partisipatori (SHIP) yang menerapkan prinsip ergonomi menurunkan kelelahan mahasiswa dalam proses perkuliahan. Dengan adanya peregangan di sela menguji OSCE reguler maka tingkat kelelahan dalam menguji dapat diturunkan. Wiradharma (2012) menyatakan bahwa kelelahan pada praktikan mengalami penurunan sebesar $20,3 \%$ pada Praktikum odontektomi berorientasi ergonomi di jurusan kedokteran gigi Universitas Mahasaraswati Denpasar.

Hasil uji paired-sample $t$ test skor keluhan muskuloskeletal sebelum menguji tidak berbeda bermakna $(p>0,05)$, ini berarti skor keluhan muskuloskeletal sesudah menguji pada Periode I (tanpa intervensi ergonomi) dengan Periode II (dengan intervensi ergonomi) adalah berbeda. Hal tersebut seperti terlihat dalam Tabel 4.

Tabel 4 Nilai Rerata Keluhan Muskuloskeletal antar Perlakuan

\begin{tabular}{ccccccc}
\hline & \multicolumn{2}{c}{ Periode I } & \multicolumn{2}{c}{ Periode II } & Nilai t & \multirow{2}{*}{ Nilai p } \\
\cline { 2 - 5 } & Rerata & SB & Rerata & SB & & \\
\hline $\begin{array}{c}\text { Sebelum } \\
\text { Menguji }\end{array}$ & 31,225 & 2,547 & 31,875 & 2,524 & 1,433 & 0,160 \\
$\begin{array}{c}\text { Sesudah } \\
\text { Menguji }\end{array}$ & 70,475 & 4,674 & 45,900 & 5,213 & 36,382 & 0,001 \\
Beda & 39,250 & 5,633 & 14,025 & 4,999 & 29,291 & 0,001 \\
\hline
\end{tabular}

Rerata skor keluhan muskuloskeletal pada Periode I (tanpa intervensi ergonomi) yaitu 39,25 dan pada Periode II (dengan intervensi ergonomi) yaitu 14,02. Terjadi penurunan keluhan muskuloskeletal pada Peridoe II sebesar 64,28\% secara signifikan $(\mathrm{p}<0,05)$ seperti terlihat pada Tabel 4. Temuan ini juga didukung oleh Sutajaya (2006) yang menyatakan bahwa pembelajaran sistemik, holistik, interdisipliner, dan partisipatori (SHIP) yang menerapkan prinsip ergonomi menurunkan keluhan muskuloskeletal mahasiswa dalam proses perkuliahan.

\section{SIMPULAN DAN SARAN}

Dari uraian di atas dapat disimpulkan bahwa ujian OSCE reguler berorientasi ergonomi yaitu istirahat aktif dengan peregangan dan minum teh manis dapat meningkatkan kinerja penguji berdasarkan indikator kinerja sebagai berikut :

1. Ujian OSCE reguler berorientasi ergonomi dapat menurunkan kebosanan pada penguji OSCE di Fakultas Kedokteran Universitas Islam Al-Azhar Mataram. 
2. Ujian OSCE reguler berorientasi ergonomi dapat menurunkan kelelahan pada penguji OSCE di Fakultas Kedokteran Universitas Islam Al-Azhar Mataram.

3. Ujian OSCE reguler berorientasi ergonomi dapat menurunkan keluhan muskuloskeletal pada penguji OSCE di Fakultas Kedokteran Universitas Islam Al-Azhar Mataram.

Proses menguji dengan menyisipkan peregangan otot dan minum teh manis sebaiknya mulai diterapkan karena sudah terbukti mampu menurunkan kebosanan, kelelahan dan keluhan muskuloskeletal para penguji OSCE. Dipandang perlu untuk memberikan mata kuliah ergonomi pada fakultas kedokteran sehingga nantinya proses kerja dokter maupun dosen di fakutas kedokteran lebih produktif dan sesuai dengan kaidah ergonomi. Perlu dilakukan penelitian yang lebih mendalam dengan menggunakan intervensi ergonomi lain dalam memecahkan masaah ergonomi pada proses ujian OSCE di fakultas kedokteran. Misalnya: pengaturan waktu, durasi dan frekuensi ujian OSCE reguler.

\section{Daftar Pustaka}

Alter, M. J. 2003. 300 Tehnik Peregangan Olahraga. Yogyakarta: Grafindo Persada
Arimbawa, IMG. 2010. Redesain Peralatan Kerja Secara Ergonomis. Denpasar: Udayana University Press.

Bakta I.M. 2000. Rancangan Penelitian. Denpasar: Fakultas Kedokteran

Universitas Udayana.

Dikti. 2006. Health Professional Education Quality Project: Pedoman Persiapan dan Penyelenggaraan

Objective Structured Clinical Examination (OSCE) untuk Dokter Dan Dokter Gigi. [cited 2014 January 14]. Available-from:URL: http://hpeq.dikti.go.id/v2/ images/Produk/Panduan Penyelenggaraan_Ujian Osce.pdf

Irwanti, NKD. 2011, Peregangan Otot Di Sela Pembelajaran Mengurangi Kebosanan, Kelelahan Dan Keluhan Muskuloskeletal Peserta Didik Kelas X, Smk Pariwisata Triatma Jaya Badung. (tesis). Denpasar: $\quad$ Program Pascasarjana Universitas Udayana.

Mangkuprawira, S. 2003. Managemen Sumber Daya Manusia Strategik. Cetakan Kedua. Jakarta: Ghalia Indonesia 
Sofwan, R. 2013. Bugar Selalu di Tempat Kerja. Jakarta: PT. Bhuana Ilmu Populer

Sutajaya, IM. 2006. Pembelajaran Melalui Pendekatan Sistemik Holistik Interdisipliner dan Partisipatori (SHIP) Mengurangi Kelelahan Keluhan Muskuloskeletal dan Kebosanan serta Meningkatkan Luaran Proses Belajar Mahasiswa Biologi IKIP Singaraja. (Disertasi). . Denpasar: Program Pascasarjana Universitas Udayana.

Wiradharma, N. 2012. Praktikum Odontektomi

Berorientasi Ergonomi Meningkatkan Kinerja Praktikan Di Jurusan Kedokteran Gigi Universitas Mahasaraswati Denpasar. (Tesis). Denpasar: Program Pascasarjana Universitas Udayana 